\title{
Purification and biochemical characterization of four iron superoxide dismutases in Trypanosoma cruzi
}

\author{
Héctor Mateo, Clotilde Marín, Gregorio Pérez-Cordón, Manuel Sánchez-Moreno/+ \\ Departamento de Parasitología, Instituto de Biotecnologia, Universidad de Granada, Severo Ochoa s/n, E-18071 Granada, España
}

Four superoxide dismutase (SOD) activities (SOD I, II, III, and IV) have been characterized in the epimastigote form of Trypanosoma cruzi. The total extract was subjected to two successive ammonium sulphate additions between 35 and $85 \%$, and the resulting fraction was purified using two continuous chromatography processes (ion exchange and filtration). Enzymes were insensitive to cyanide but sensitive to hydrogen peroxide, properties characteristic of iron-containing SODs. The molecular masses of the different SODs were $20 \mathrm{kDa}$ (SOD I), $60 \mathrm{kDa}$ (SOD II), $50 \mathrm{kDa}$ (SOD III) and $25 \mathrm{kDa}(\mathrm{SOD} I \mathrm{~V}$ ), whereas the isoelectric points were 6.9, 6.8, 5.2 and 3.8, respectively. Subcellular location and digitonin experiments have shown that these SODs are mainly cytosolic, with small amounts in the lowmass organelles (SOD II and SOD I) and the mitochondrion (SOD III), where these enzymes play an important role in minimizing oxidative damage.

Key words: superoxide dismutase - T. cruzi - chromatography - subcellular localization

Trypanosoma cruzi is a blood-borne flagellated protozoan responsible for Chagas disease, a vectorially transmitted disease that, in its chronic form, affects more than 16 million people, especially in Latin America, with high morbidity and a rate of more than half a million new cases every year, most of them children (WHO 2002). The lack of fast and reliable diagnostic methods together with the strain biodiversity and therapeutic difficulties make it a major health problem in which only prophylactic measures are effective (Binder et al. 1999, Urbina \& Docampo 2004).

The presence of the parasite in a new host triggers a series of mechanisms intended to eliminate the foreign agents. Beyond all doubt, one of the most important host strategies to combat infection consists of the production of free radicals (highly reactive chemical species able to denaturalize the parasitic membranes), such as the superoxide anion $\left(\mathrm{O}_{2}^{-}\right)$, hydrogen peroxide $\left(\mathrm{H}_{2} \mathrm{O}_{2}\right)$, peroxynitrite $\left(\mathrm{ONOO}^{-}\right)$and hydroxyl radical $\left(\mathrm{HO}^{-}\right)$(Piñeyro et al. 2005). It has been reported that trypanosomatids are devoid of or extremely deficient in catalase and seleniumdependent glutathione peroxidase, the most common antioxidant defences in eukaryotes. Instead, they possess an array of enzyme-mediated detoxifying mechanisms, such as superoxide dismutase (SOD), three trypanothione-dependent peroxidases, a glutathione-spermidinedependent peroxidase, a tryparedoxin peroxidase, two non-selenium-glutathione peroxidases and the ascorbate-dependent hemoperoxidase, meant to maintain the

Financial support: CGL2006-27889-E/BOS, Ministerio de Ciencia y Tecnología

+Corresponding author: msanchem@ugr.es

Received 28 December 2007

Accepted 7 May 2008 intracellular reducing environment and, thereby, to allow the parasite to evade the immune response (Wilkinson \& Kelly 2003, Turrens 2004, Hernández et al. 2006).

SODs are a group of antioxidant metalloenzymes that eliminate superoxide radicals by dismutation into $\mathrm{H}_{2} \mathrm{O}_{2}$ and molecular oxygen. SODs have strong antioxidant properties and have been shown to protect normal cells as well as a number of pathogens from reactive oxygen species (ROS). Classically, SODs have been classified into three types according to the metal cofactor bound at the active site: copper-zinc (Cu-Zn-SOD) and manganese SODs (Mn-SOD), (both of which are present in most prokaryotes and eukaryotes, including humans), and iron SODs (Fe-SOD), detected in some prokaryotes, protozoans and chloroplasts of plants and algae. In recent years, a nickel SOD activity has also been described in Streptomyces spp. (Youn et al. 1996).

To date, the presence of an iron-containing SOD activity has been reported in numerous trypanosomatids, including T. cruzi (Ismail et al. 1997, Temperton et al. 1997, Villagrán et al. 2005), Trypanosoma brucei (Dufernez et al. 2006, Wilkinson et al. 2006), different species of the genus Leishmania (Leishmania aethiopica, Genetu et al. 2006, Leishmania chagasi, Paramchuk et al. 1997, and Leishmania donovani, Bogdan et al. 1990), Crithidia fasciculata (Le Trant et al. 1983) and Phytomonas spp. (plant trypanosomatid) (Marín et al. 2004), playing an important role in the survival and growth of the parasites.

In a previous study, we detected four SOD activities in epimatigote forms of T. cruzi, for which different isoelectric points (pI) are known (Villagrán et al. 2005), but these have been neither purified nor biochemically characterized. Thus, this is the first study to focus on the purification and biochemical characterization of SODs in T. cruzi.

\section{MATERIALS AND METHODS}

Organisms and media - Epimastigotes of T. cruzi (Maracay strain isolated in Maracay, Venezuela) were grown in axenic Grace's insect medium $\left(\right.$ Gibco $\left.^{\circledR}\right)$ supple- 
mented with $10 \%$ heat-inactivated fetal bovine serum at $28^{\circ} \mathrm{C}$ in tissue-culture flasks until the cultures reached a density of approximately $1 \times 10^{7}$ parasites $/ \mathrm{ml}$. Cells were collected at the logarithmic growth phase by centrifugation (1500 $\mathrm{g}$ for $10 \mathrm{~min}$ at room temperature).

Extraction and purification of the SODs - The pellets of cells $(0.5-0.6 \mathrm{~g} \mathrm{mw} / \mathrm{ml})$ were washed twice and resuspended in $3 \mathrm{ml}$ ice-cold STE buffer $(0.25 \mathrm{M}$ sucrose, $25 \mathrm{mM}$ Tris-HCl, $1 \mathrm{mM}$ EDTA, $\mathrm{pH}$ 7.8; buffer 1). The cells were disrupted by three consecutive cold cycles of sonic disintegration ( $30 \mathrm{~s}$ each at 60 volts, 1 min between cycles), and inspection by light microscopy was used to verify the complete cellular lysis; after this, the sample was centrifuged at $2500 \mathrm{~g}$ for $5 \mathrm{~min}$ at $4^{\circ} \mathrm{C}$. The pellet was washed twice with buffer 1 and then centrifuged $(2500 \mathrm{~g}$ for $10 \mathrm{~min}$ at $4^{\circ} \mathrm{C}$ ) to obtain a total supernatant fraction of approximately $10 \mathrm{ml}$ (Fraction H). Degradation due to protease activities present in the supernatant was minimized by the addition of $25 \mu \mathrm{l}$ of protease inhibitor (Protease Inhibitor Complete Mini, Roche ${ }^{\circledR}$ ). This protein fraction was subjected to two ice-cold consecutive ammonium sulphate additions between 35 and $85 \%(\mathrm{w} / \mathrm{v})$ salt and centrifuged $\left(9000 \mathrm{~g}\right.$ for $25 \mathrm{~min}$ at $4^{\circ} \mathrm{C}$ ) to obtain a precipitate that was finally redissolved in $2.5 \mathrm{ml}$ of $20 \mathrm{mM}$ potassium phosphate buffer, $\mathrm{pH} 7.8$, containing 1 mM EDTA (buffer 2), and desalted in a Sephadex G-25 column (Pharmacia, PD 10) previously equilibrated with $25 \mathrm{ml}$ buffer 2, bringing it to a final volume of $3.5 \mathrm{ml}$ (Fraction P85) (Marín et al. 2004).

The P85 fraction was applied to a QAE-Sephadex A-50 column $(30 \times 2 \Phi \mathrm{cm})$ equilibrated with buffer 2 . The column was extensively washed with the same buffer, and the adsorbed proteins were eluted with a linear gradient of $\mathrm{KCl}(0-0.6 \mathrm{M})$. Fractions exhibiting SOD activity (peaks Q1, Q2 and Q3) were pooled and concentrated by ultrafiltration in Microcon ${ }^{\circledR}$ filter tubes $\left(\mathrm{Amicon}^{\circledR}\right.$ ) at $11200 \mathrm{~g}$ for $30 \mathrm{~min}$. The peaks were applied separately to a G-75 Sephadex molecular sieve chromatography column $(75 \times 1.6 \Phi \mathrm{cm})$ equilibrated with buffer 2. The enzyme was eluted with $200 \mathrm{ml}$ of the same buffer solution. The fractions with the highest specific SOD activity (SOD I, SOD II, SOD III and SOD IV) were again collected, concentrated (to a concentration of $2 \mathrm{mg} / \mathrm{ml}$ ), and used for the experiments described below.

Subcellular location of SODs - A homogenate of the Maracay strain of $T$. cruzi was prepared by grinding the cell paste with silicon carbide abrasive $\left(\right.$ Carborundum $\left.{ }^{\circledR}\right)$, as described by Steiger et al. (1980). Protein concentrations and SOD activities were measured in fractions recovered by differential centrifugation following the method of Marín et al. (2004). Fractions H (homogenate), $\mathrm{N}$ (nuclear), L (high-mass organelles), $\mathrm{S}$ (low-mass organelles), M (microsomal) and C (cytosolic) were recovered. Recovery (based on the sum of fractions) and relative specific activity (RSA) were calculated. For the correct identification of the subcellular fractions, we checked specific marker enzymes according to Uttaro and Opperdoes (1997), i.e., pyruvate kinase for the cytosol, hexokinase for the glycosome and alanine transferase for the mitochondria.
Digitonin treatment of intact cells - The cell suspensions were diluted to a density corresponding to $2 \mathrm{mg}$ protein $/ \mathrm{ml}$ in buffer 1 containing increasing concentrations of digitonin. After incubation for $5 \mathrm{~min}$ at $4^{\circ} \mathrm{C}$, suspensions were centrifuged. Aliquots of the supernatants were used to assay the various enzymatic activities according to Uttaro and Opperdoes (1997).

Protein determination - The protein content of fractions $\mathrm{H}$ and $\mathrm{P} 85$, the peaks and all elution fractions resulting from the two columns were quantified using the Bio$\operatorname{Rad}^{\circledR}$ Bradford test, which uses bovine serum albumin (BSA) as a standard.

Enzyme assay - SOD activity was performed on fractions $\mathrm{H}, \mathrm{P} 85$ and elutions by spectrometric measurement of NBT-UV light oxidation according to the method described by Beyer and Fridovich (1987). Buffer $3(50 \mathrm{mM}$ potassium phosphate, $\mathrm{pH}$ 7.8) was chosen for these determinations. Pyruvate kinase, hexokinase and alanine aminotransferase activities were determined according to Uttaro and Opperdoes (1997).

Determination of molecular weight - Apparent molecular weights of the purified SODs (peaks Q1, Q2 and Q3) were calculated by native gel electrophoresis in PhastGel Homogeneous $12.5 \%$ gels. The standard mixture of proteins used as markers (LMW Calibration Kit, Pharmacia ${ }^{\circledR}$ ) contained phosphorylase B (94 kDa), BSA (67 kDa), ovalbumin $(43 \mathrm{kDa})$, carbonic anhydrase $(30 \mathrm{kDa})$, soybean trypsin inhibitor $(20 \mathrm{kDa})$ and $\alpha$-lactalbumin $(14.4 \mathrm{kDa})$. The gels were stained for protein with the silver staining solution as described in the PhastSystem handbook, and the SOD activity was revealed with the method described previously.

Determination of the $\mathrm{pI}$ - Isoelectric focusing (IEF) in polyacrylamide PhastGel IEF 3-9 gels were used to determine the $\mathrm{pI}$ of components of fraction P85 as described by Bécuwe et al. (1996). The markers used were trypsinogen (9.3), lentil-lectin acidic band (8.15), horse heart myoglobin (6.8), carbonic anhydrase II (5.9), $\alpha$-lactoglobulin A (5.1), soybean trypsin inhibitor (4.6) and amyloglucosidase from Aspergillus niger (3.6) $\left(\right.$ Pharmacia $\left.^{\mathbb{R}}\right)$. The markers were stained for protein, and the activity was revealed as described previously.

Inhibition studies - Specific inhibitors with known effects on the different SOD metal cofactors (cyanide and $\mathrm{H}_{2} \mathrm{O}_{2}$ ) were employed. For the cyanide assays, samples were applied to an IEF 3-9 polyacrylamide gel, and then the SOD activity was revealed by adding $20 \mathrm{mM}$ sodium cyanide to the revealing solution. For the $\mathrm{H}_{2} \mathrm{O}_{2}$ inhibition test, $\mathrm{H}_{2} \mathrm{O}_{2}$ was added to the gel and incubated at room temperature for $15 \mathrm{~min}$. Then, the gel was stained for SOD activity as described above.

\section{RESULTS}

The epimastigote lysate (Fraction H) from T. cruzi was processed to yield the $\mathrm{P} 85$ fraction, which was applied to a QAE-Sephadex A-50 ion exchange chromatography column, revealing the existence of three SOD activity peaks: peak Q1 (fractions 9-20), Q2 (fractions 26-40) and Q3 (fractions 44-55) (Fig. 1A). IEF 3-9 polyacrylamide 

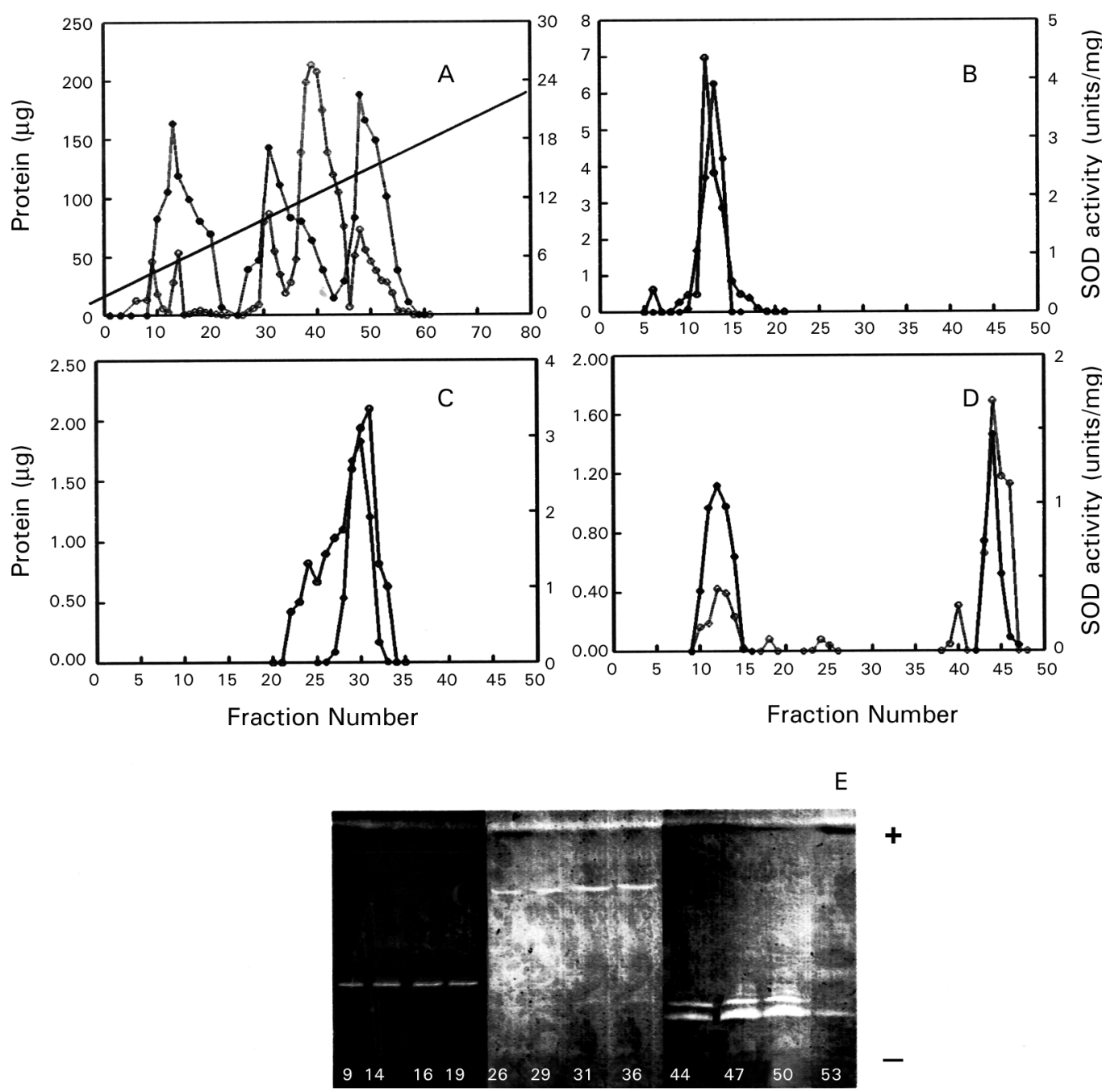

Fig. 1: purification profiles of superoxide dismutases (SODs) from Trypanosoma cruzi Maracay strain. A: QAE-Sephadex ion-exchange chromatography; B: Sephadex G-75 sieve chromatography of SODIII; C: Sephadex G-75 molecular sieve chromatography of SODIV; D: Sephadex G-75 molecular sieve chromatography of SODII and SODI; E: isoelectric focusing gel electrophoresis pI 3-9 of the fraction eluted by QAE-Sep-

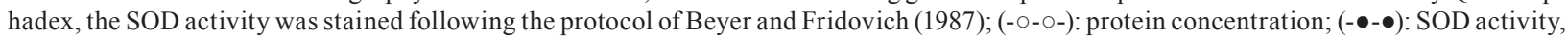
(--): gradient 0-0.6 M KCl.

gel electrophoresis of the fractions eluted from the QAESephadex A-50 column was also performed to visualize the SOD activities (Fig. 1E). The three active peaks (peaks Q1, Q2 and Q3) were collected, desalted, concentrated, and further purified separately by Sephadex G-75 molecular-sieve chromatography. Purification of peak Q1 resulted in a new peak called SOD III, located between fractions 11 and 14 (Fig. 1B), peak Q2 purification yielded a new peak called SOD IV, located between fractions 25 and 35 (Fig. 1C), whereas the purification of peak Q3 yielded two new peaks called SOD II (fractions 8-15) and SOD I (fractions 43-46) (Fig. 1D). Table summarizes the purification, indicating that SOD III was purified 336 times to a specific activity of about $7380.89 \mathrm{U} / \mathrm{mg}$ of protein; SOD IV was purified 489 times to a specific activity of about $10751.72 \mathrm{U} / \mathrm{mg}$ of protein; SOD II was purified to a specific activity of $13956.52 \mathrm{U} / \mathrm{mg}$ of protein (purification rate 635), whereas SOD I was purified 424 times to a total activity of 9,446 U/mg.
Molecular weights were also determined by native electrophoresis on PhastGel Homogeneous 20\% gels, showing that the SODs had molecular masses of approximately $50 \mathrm{kDa}$ (SOD III), $25 \mathrm{kDa}$ (SOD IV), $60 \mathrm{kDa}$ (SOD II) and $20 \mathrm{kDa}$ (SOD I) (Fig. 2A, lanes- 1, 2, 3, respectively). The four SODs had different pI: SOD I had a pI of 6.9, and the pI of SOD II was approximately 6.8, whereas SOD III and SOD IV had pIs of 5.25 and 3.8, respectively (Fig. 2B, lane 4).

We performed studies with specific inhibitors that have known effects on SODs containing various cofactors: $\mathrm{Cu} / \mathrm{Zn}, \mathrm{Mn}$ or Fe. All SODs proved to be inhibited by $\mathrm{H}_{2} \mathrm{O}_{2}$ and not by sodium cyanide (Fig. 2B, lanes- 5,6 ), and this behaviour is characteristic of iron-containing enzymes.

To determine the subcellular localization of these SODs, we fractionated T. cruzi cells by differential centrifugation. Protein determinations and SOD activity assays were performed on every fraction, and RSA and recovery percentages were calculated. The four isoen- 
TABLE

Superoxide dismutase (SOD) purification from epimastigotes of Trypanosoma cruzi Maracay strain

\begin{tabular}{|c|c|c|c|c|c|}
\hline Fraction & $\begin{array}{c}\text { Total } \\
\text { protein (mg) }\end{array}$ & $\begin{array}{l}\text { Total activity }^{a} \\
\text { (Units } \pm \text { SD) }\end{array}$ & $\begin{array}{c}\text { Specific activity }^{b} \\
\text { (Units/mg prot } \pm \text { SD) }\end{array}$ & Purification & Yield (\%) \\
\hline Homogenate & 43.171 & $661.40 \pm 42.33$ & $22.27 \pm 1.72$ & 1 & 100 \\
\hline P85 & 3.832 & $469.80 \pm 18.23$ & $122.63 \pm 4.76$ & 6 & 70 \\
\hline Peak Q1 & 0.127 & $296.51 \pm 6.42$ & $2329.69 \pm 25.31$ & 104 & 44 \\
\hline Peak Q2 & 0.922 & $217.63 \pm 13.08$ & $1236.01 \pm 14.18$ & 55 & 33 \\
\hline Peak Q3 & 0.520 & $206.63 \pm 14.52$ & $397.36 \pm 50.06$ & 18 & 31 \\
\hline SOD I & 0.001 & $12.28 \pm 0.09$ & $9446.15 \pm 7.075$ & 424 & 2 \\
\hline SOD II & 0.001 & $9.63 \pm 0.67$ & $13956.52 \pm 971.01$ & 635 & 1 \\
\hline SOD III & 0.016 & $118.98 \pm 1.72$ & $7380.89 \pm 106.17$ & 336 & 18 \\
\hline SOD IV & 0.010 & $108.71 \pm 1.00$ & $10751.72 \pm 98.91$ & 489 & 16 \\
\hline
\end{tabular}

$a$ : SOD activity determined by the technique of Beyer and Fridovich (1987); $b$ : SD is the standard deviation of the mean of five determinations.
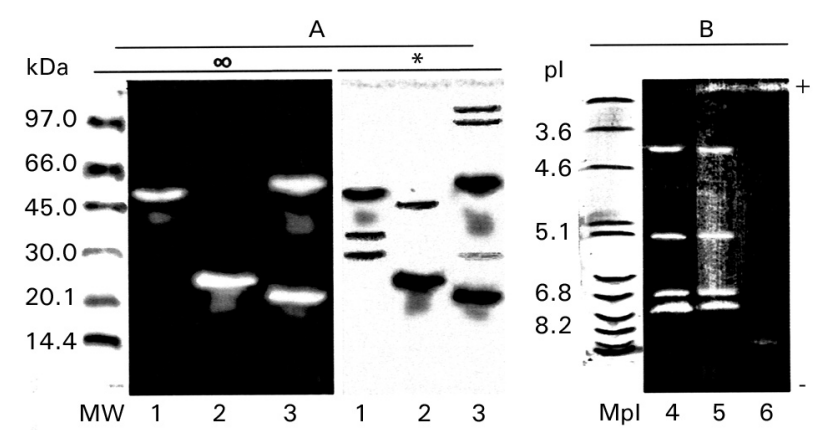

Fig. 2: electrophoresis of the purified enzymes. A: native gel electrophoresis in PhasGel Homogeneous $12.5 \%$; B: determination of the metal cofactor of Trypanosoma SODs by inhibition studies performed in isoelectric focusing gel electrophoresis pI 3-9. Lanes - 1: SODIII (peak Q1, $2 \mu \mathrm{g}$ ); 2: SODIV (peak Q2, $2 \mu \mathrm{g}$ ); 3: SODII and SODI (peak Q3, $2 \mu \mathrm{g})$; 4: fraction P85; 5: fraction P85 with 20 mM KCN; 6: fraction P85 with $5 \mathrm{mM} \mathrm{H}_{2} \mathrm{O}_{2}$. MpI: isoelectric point marker; MW: molecular weight marker proteins; $(\infty)$ : silver staining; (*): SOD activity revealed according to Beyer and Fridovich (1987).

zymes were localized to the cytoplasmic fraction. Furthermore, SOD III and SOD IV were also present in the glycosomal fraction and SOD I, in smaller amounts, in the large organelles (the mitochondrion), with a recovery percentage of $91.8 \%$ (Fig. 3A). This distribution was also demonstrated by IEF ( $\mathrm{pI}$ 3-9) and activity assay by the above-mentioned technique (Fig. 3B). This observation was corroborated by digitonin titration experiments using pyruvate kinase, hexokinase and alanine aminetransferase as markers for soluble, glycosomal and mitochondrial fractions, respectively (Fig. 3C). It was noteworthy that $24 \%$ of the activity was not solubilized, even at high digitonin concentrations.

\section{DISCUSSION}

For the first time, we report the partial purification of the SOD activities from the epimastigote form of $T$. cruzi. The SOD activity identification is possible only under the native conditions of the protein; thus, we have detected four different isoenzymes by IEF 3-9 and native electrophoresis. According to Villagrán et al. (2005), we have found different pI: 6.9, 6.8, 5.2 and 3.8 for SOD I, SOD II, SOD III and SOD IV, respectively. The pIs ob- served disagree with the predicted pIs of a single subunit in the T. cruzi genome database (http://www.genedb.org/ genedb/tcruzi) because of the monomer-monomer interactions, which would involve and/or shield charged residues. The molecular masses determined were $20 \mathrm{kDa}$ for SOD I, $60 \mathrm{kDa}$ for SOD II, $50 \mathrm{kDa}$ for SOD III and $25 \mathrm{kDa}$ for SOD IV. To date, the molecular weights of SODs in trypanosomatids have been determined as monomers in denaturing gels for T. cruzi and T. brucei (around 20 and $24 \mathrm{kDa}$ ) (Temperton et al. 1996, Kabiri \& Steverding 2001, Dufernez et al. 2006), and, for native enzymes, the mass has been shown for Phytomonas spp. (24 and $66 \mathrm{KDa}$ ) by Marín et al. (2004). Thus, the apparent mass of 50 and $60 \mathrm{kDa}$ of $T$. cruzi SOD I and III is probably the result of the dimeric form since SODs of $50 \mathrm{kDa}$ or higher have not been found in any of the trypanosomatid genomes (http:/www.sanger.ac.uk/ Projects/Protozoa/).

In Trypanosomatidae, different studies have reported the presence of SOD activities. T. brucei (Dufernez et al. 2006, Wilkinson et al. 2006), Leishmania spp. (Bogdan et al. 1990, Genetu et al. 2006), and Phytomonas spp. (Marín et al. 2004), and many other protozoans (Plasmodium falciparum, Entamoeba histolytica, Toxoplasma gondii or Trichomonas spp.) have been shown to possess SOD activities in at least one stage of their life cycle (Sibley et al. 1986, Fairfield et al. 1988). To date, in T. cruzi, some studies have also reported the existence of two SOD activities (Ismail et al. 1997). Nevertheless, this is the first study to focus on the purification and biochemical characterization of the SODs, while no reference is available in the literature for the two other newly identified activities.

Four peaks of SOD activity were isolated by ion exchange chromatography and identified. Each peak was further purified separately by filtration chromatography, giving rise to a total of four SOD activities [called SOD I, II, III and IV, according to the nomenclature used by Villagrán et al. (2005)]. This is consistent with the results revealed by IEF since the P85 fraction showed four bands of SOD activity. Throughout all of these purification processes, activity was steadily lost, so we employed the minimum total duration needed to optimise the purification yield. 


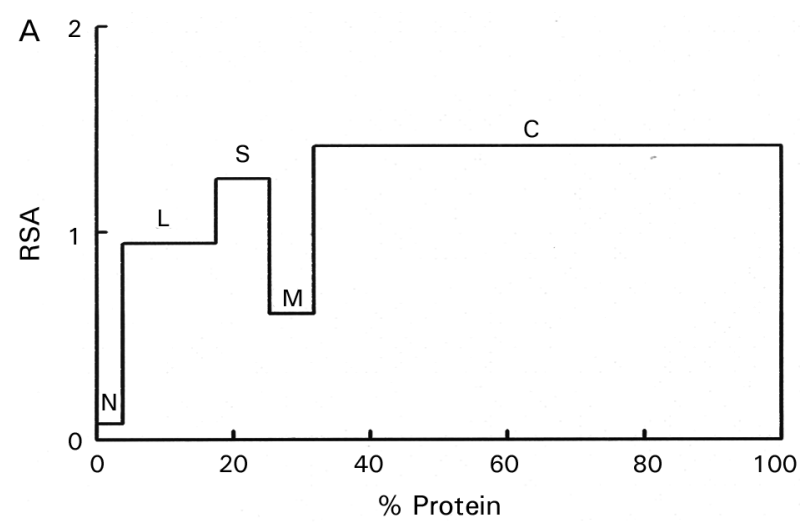

B
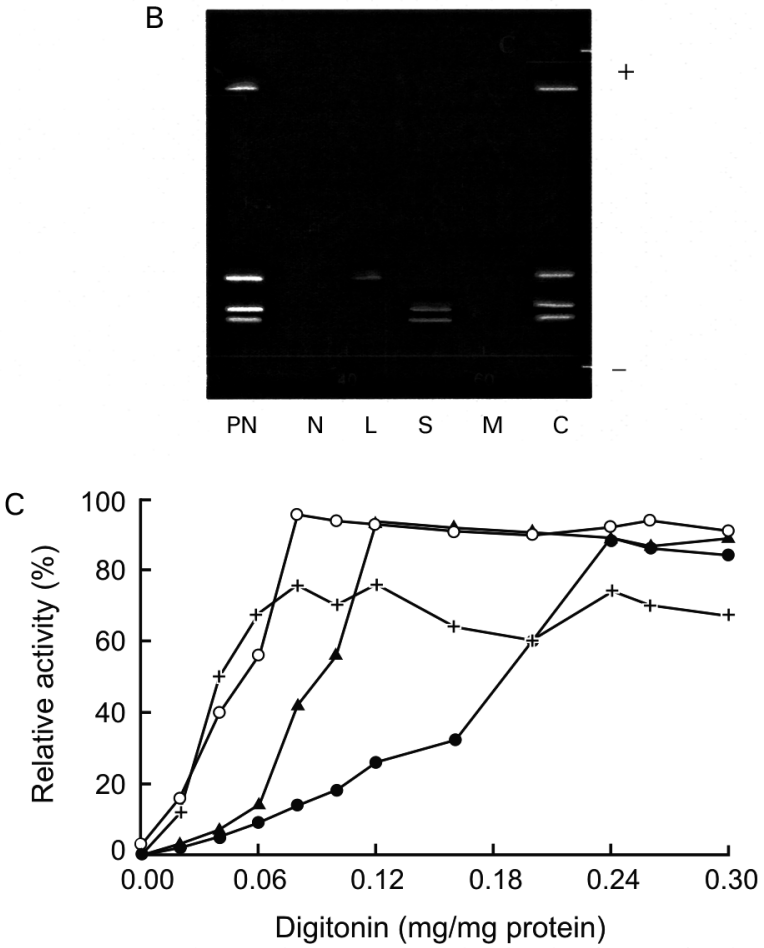

Fig. 3: distribution profile of SOD activity in the fractions from the differential centrifugation. A: SOD activity was determined in the different fractions according to the method of Beyer and Fridovich (1987). The relative specific activity (RSA), ratio between the percentage of total activity and percentage of total protein for each fraction (Y-axis) is plotted against the cumulative percentage of protein (X-axis); B: activity staining by isoelectric focusing. Lanes - C: cytoplasmic fractions; L: large organelle fraction; M: microsomal; N: nuclear; PN: postnuclear fraction; S: small organelle fraction. C: digitonin-titration experiment of the SOD activity (-+-+-); Pyruvate ki-

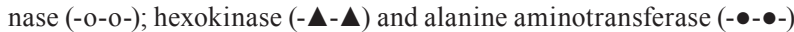
as markers for soluble, glycosomal and mitochondrion localizations.

As in other SODs studied in pathogenic kinetoplastids, inhibition assays against specific inhibitors revealed behaviour typical of iron-linked enzymes (Temperton et al. 1996, Ismail et al. 1997, Paramchuk et al. 1997, Kabiri $\&$ Steverding 2001).

The subcellular location of SODs in the Maracay strain of $T$. cruzi has demonstrated that these enzymes have specific locations within the cell. Quality control for impurities in the different subcellular fractions was performed by checking the presence of marker enzymes (pyruvate kinase, hexokinase and alanine aminotransferase), according to Uttaro and Opperdoes (1997). The compartmentalization becomes significant if we accept that the main role of SOD is to detoxify endogenous superoxide anions and that the different biochemical processes that produce oxidizing agents inside the cell may need various antioxidant systems to protect macromolecules and organelles from oxidative damage. SOD is mainly a cytosolic enzyme, although a certain SOD activity is also localized in the glycosomal and mitochondrial fractions. This fact has precedents, as in C. fasciculata, a non-pathogenic trypanosomatid, which has two SOD isoenzymes, one located in the cytosol and the other in the mitochondrion (Quesada et al. 2001). Also, in T. brucei, four activities with different subcellular locations were detected, one in the cytosol, another in the glycosomes and the other two in the mitochondrion (Dufernez et al. 2006). SOD is presumably synthesised in the cytosol and can remain there and/or be transported to the interior of certain organelles, as happens in the cases of T. brucei (Dufernez et al. 2006) and Leishmania spp. (Genetu et al. 2006). The digitonin experiments revealed that $24 \%$ of the total activity is not even solubilized at high concentrations of digitonin, indicating that it would be a membrane-related activity (which would be lost during the fractionation process). This fact is consistent with a previous study performed by us on Phytomonas sp., in which approximately $20 \%$ of the total SOD activity seemed to be associated with membranes or even excreted (Marín et al. 2006). Despite lacking catalase and glutathione peroxidase, the main antioxidant defences against ROS in eukaryotic cells, T. cruzi possess SOD and other highly efficient detoxifying mechanisms aimed at neutralizing moderate increments of ROS (Wilkinson et al. 2000, Wilkinson \& Kelly 2003, Hernández et al. 2006). The presence of various SOD isozymes in different locations within the cell ensures more effective action against eventual increases in ROS intracellular levels, maintaining a favourable reducing environment inside the cell, and this could be considered a potential virulence factor, playing a major role in the survival of the pathogen inside the host cell.

The study of these newly identified SODs, their biochemical characterization and the scope of their role inside the parasite cell, or beyond, in the interactions with the host cells, together with the comparison of the SOD genes in order to establish the significant differences and novelties among SODs throughout Trypanosomatidae, would constitute the next step in future research on the biochemical and immunological paths that enable the survival of the species.

\section{ACKNOLEDGEMENTS}

To David Nesbitt for the English translation of the manuscript.

\section{REFERENCES}

Bécuwe P, Gratepanche S, Fourmaux MN, Van Beeumen J, Samyn B, Mercereau-Puijalon O, Touzel JP, Slomianny C, Camus D, Dive D 1996. Characterization of iron-dependent endogenous superoxide dismutase of Plasmodium falciparum. Mol Biochem Parasitol 76: 125-134. 
Beyer WF, Fridovich I 1987. Assayaing for superoxide dismutase activity: Some large consequences of minor changes in conditions. Anal Biochem 161: 559-566.

Binder S, Levitt AM, Sacks JJ, Hughes JM 1999. Emerging infectious diseases: Public health issues for the 21st Century. Science 284: 1311-1313.

Bogdan C, Rollinghov M, Solbach W 1990. Evasion strategies of Leshmania parasites. Parasitol Today 6: 183-186.

Dufernez F, Yernaux C, Gerbod D, Noël C, Chauvenet M, Wintjens R, Edgcomb V, Capron M, Opperdoes FR, Viscogliosi E 2006. The presence of four iron-containing superoxide dismutase isozymes in Trypanosomatidae: Characterization, subcellular localization and phylogenetic origin in Trypanosoma brucei. Free Radic Biol Med 40: 210-225.

Fairfield A, Abosh A, Ranz A, Eaton J, Meschnick S 1988. Oxidant defence enzymes of Plasmodium falciparum. Mol Biochem Parasitol 30: 77-82.

Genetu A, Gadixa E, Aseva A, Barr S, Lakew M, Jirata D, Kuru T, Hunegnaw M, Gedamu L 2006. Leishmania aethiopica: strain identification and characterization of superoxide dismutase-B genes. Exp Parasitol 113: 221-226.

Hernández SM, Sánchez MS, Schwarc de Tarlovsky MN 2006. Polyamines as a defense mechanism against lipoperoxidation in Trypanosoma cruzi. Acta Trop 98: 94-102.

Ismail SO, Paramchuck WJ, Bhatia JA, Gedamu L 1997. Molecular cloning and characterization of two iron superoxide dismutase cDNAs from Trypanosoma cruzi: differential and stage specific expression. Mol Biochem Parasitol 86: 187-197.

Kabiri M, Steverding D 2001. Identification of a developmentally regulated iron superoxide dismutase of Trypanosoma brucei. Biochem J 360: 173-177.

Le Trant N, Meshnich SR, Kitchener K, Eaton JW, Cerami A 1983. Iron-containing superoxide dismutase from Crithidia fasciculata. Purification, characterization and similarity of leishmanial and trypanosomal enzymes. J Biological Chem 258: 125-130.

Marín C, Rodríguez-González I, Sánchez-Moreno M 2006. Identification of excreted iron superoxide dismutase for the diagnosis of Phytomonas. Mem Inst Oswaldo Cruz 101: 649-654.

Marín C, Rodríguez-González I, Hitos A, Rosales MJ, Dollet M, Sánchez-Moreno M 2004. Purification and characterization of two iron superoxide disputases of Phytomonas $s p$. isolated form Euphorbia characias (Plant Trypanosomatids). Parasitology 129: 79-86.

Paramchuk WJ, Ismail SO, Bhatia A, Gedamu L 1997. Cloning, characterization and overexpression of two iron superoxide dismutase cDNAs from Leishmania chagasi: Role in pathogenesis. Mol Biochem Parasitol 90: 203-221.
Piñeyro MD, Pizarro JC, Lema F, Pritsch O, Cayota A, Bentley GA, Robillo C 2005. Crystal structure of the tryparedoxin peroxidase from the human parasite Trypanosoma cruzi. J Struct Biol 150: $11-22$.

Quesada JM, Entrala E, Fernández-Ramos C, Marín C, SánchezMoreno M 2001. Phytomonas spp.: superoxide dismutase in plant trypanosomes. Mol Biochem Parasitol 115: 123-127.

Sibley LD, Lawson R, Weidner E 1986. Superoxide dismutase and catalase in Toxoplasma gondii. Mol Biochem Parasitol 19: 83-87.

Steiger RF, Opperdoes FR, Bontemps J 1980. Subcellular localization and fractionation of Trypanosoma brucei blood streamforms with special reference of hydrolases. Eur J Biochem 105: 163-175.

Temperton NJ, Wilkinson SR, Kelly JM 1996. Cloning of an Fesuperoxide dismutase gene homologue from Trypanosoma cruzi. Mol Biochem Parasitol 76: 339-343.

Temperton NJ, Wilkinson SR, Kelly M 1997. Cloning of a Fe-superoxide dismutase homologue from Trypanosoma cruzi. Mol Biochem Parasitol 90: 103-221.

Turrens J 2004. Oxidative stress and antioxidant defenses: A target for the treatment of diseases caused by parasitic protozoa. Mol Aspects Med 25: 211-220.

Urbina JA, Docampo R 2004. Specific chemotherapy of Chagas disease. Trends Parasitol 19: 495-501.

Uttaro AD, Opperdoes FR 1997. Purification and characterization of a novel isopropanol dehydrogenase from Phytomonas sp. Mol Biochem Parasitol 8: 213-219.

Villagrán ME, Marín C, Rodríguez-González I, De Diego JA, Sánchez-Moreno M 2005. Use of a iron superoxide dismutase excreted by Trypanosoma cruzi in the diagnosis of chagas disease: seroprevalence in rural zones of the state of Queretaro, Mexico. Am J Trop Med Hyg 73: 510-516.

Wilkinson SR, Kelly JM 2003. The role of glutathione peroxidases in trypanosomatid. J Biol Chem 384: 517-525.

Wilkinson SR, Prathalingam R, Taylor MC, Ahmed A, Horn D, Kelly JM 2006. Functional characterization of the iron superoxide dismutase gene repertoire in Trypanosoma brucei. Free Radic Biol Med 40: 198-209.

Wilkinson SR, Temperton NJ, Mondragon A, Kelly JM 2000. Distinct mitochondrial and cytosolic enzymes mediate trypanothionedependent peroxide metabolism in Trypanosoma cruzi. J Biol Chem 275: 8220-8225.

WHO- World Health Organization 2002. Control of Chagas Disease, WHO Technical Report Series No. 905, Geneva, p. 1-35.

Youn HD, Kim EJ, Roe JH, Hag YC, Kang SO 1996. A novel nickelcontaining superoxide dismutase from Streptomyces spp. Biochem J 318: 889-896. 